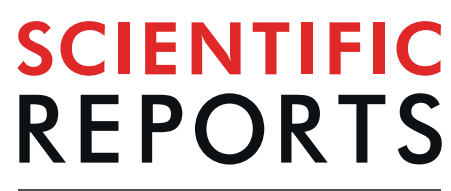

natureresearch

\title{
Analysis of Dose-response Relationship between BMI and Hypertension in Northeastern China Using Restricted Cubic Spline Functions
}

\author{
Yangming $\mathrm{Qu}^{1}$, HuiKun $\mathrm{Niu}^{2,3}, \mathrm{Lu} \mathrm{Li}^{2}$, Meiqi $\mathrm{Li}^{2}$, Shoumeng Yan ${ }^{2}$, Meng $\mathrm{Li}^{2}$, Shan Jiang ${ }^{2}$, \\ Xiaoyu $\mathrm{Ma}^{2}, \mathrm{Bo} \mathrm{Li}^{2 *} \& \mathrm{Hui} \mathrm{Wu}^{1 *}$
}

High body mass index (BMI) was significantly associated with hypertension. The purpose of this study is to investigate the association between BMI and hypertension in people in northeast China. Our study was a cross-sectional study conducted from June to August 2012. According to multistage, stratified cluster sampling, a total of 21435 inhabitants aged between 18 and 79 years in Jilin Province were selected randomly. The prevalence of hypertension was $35.66 \%$ overall. After adjusting for potential confounders, the multivariable-adjusted odds ratios for the BMI- hypertension association for overweight and obesity were 2.503 (95\% confidence interval $=1.912-2.204)$ and 4.259 (95\% confidence interval $=3.883-4.671$ ). The results of multivariable restricted cubic spline regression analysis showed that there was a non-linear relationship between the continuous change of $\mathrm{BMI}$ and hypertension $(P<0.001)$ after adjusting the confounding factors of different genders and age groups, which indicated that there was an adjusted dose-response association between continuous BMI and hypertension.

Hypertension is a multifactorial disease associated with modifiable and non-modifiable risk factors, among which, modifiable factors are obesity, excessive sodium intake, physical exercise in activity and others, non-modifiable factors are age, sex, ethnicity, and genetics and so on ${ }^{1}$. In 2012, noncommunicable diseases contributed to $68 \%$ of worldwide death, and as achronic non-communicable disease, hypertension has become an enormous public health problem due to its high prevalence and low rate of control ${ }^{1}$. The prevalence of hypertension is on the rise across the African continent, and in South Africa, some populations reported rates as high as $46 \%{ }^{2}$.

In China, the problem of hypertension challenges the population health because of its high prevalence among adults $^{3-6}$.Approximately 320 million people accounting for nearly $30 \%$ of the population 18 years old and older have hypertension in China, and among them, $<5 \%$ have their blood pressure under control ${ }^{4,6}$.

A high-salt diet is clearly associated with hypertension ${ }^{7}$, whereas salt intake is a major source of sodium in the general population ${ }^{8}$. A higher sodium intake can make blood pressure rise, which be defined as sodium sensitivity ${ }^{9}$. Genetic aspect, for example, angiotensin converting enzyme (ACE) gene polymorphisms, as a key element in therenin-angiotensin-aldosterone system, is also associated with hypertension ${ }^{10}$.

In worldwide, the prevalence of overweight and obesity constantly rising and has became a global pandemic. In the United States, the 2011-2012 National Health and Nutrition Examination Survey displayed that approximately $16.9 \%$ of youth and $34.9 \%$ of adults were diagnosed with obesity ${ }^{11}$. In China, from 1980 to 2013 , the combined age-standardized prevalence of overweight and obesity in men and women over the age of 20 was $28.3 \%$ and $27.4 \%$, respectively ${ }^{12}$. Several studies have reported that there is a link between blood pressure increase and weight gain ${ }^{13}$. Data from NHANES showed that the prevalence of hypertension in obese people is significantly

\footnotetext{
${ }^{1}$ Department of Neonatology, The First Hospital of Jilin University, 71 Xinmin Street, Changchun, 130021, China. ${ }^{2}$ Department of Epidemiology and Biostatistics, Jilin University School of Public Health, 1163 Xinmin Street, Changchun, 130021, China. ${ }^{3}$ Shijiazhuang Pharmaceutical Group Zhongqi Pharmaceutical Technology (Shijiazhuang) Co., Ltd, Shijiazhuang, China. *email: li_bo@jlu.edu.cn; wuhui97@126.com
} 
higher than that in the general population ${ }^{14}$. A prospective analysis also showed that the high prevalence of hypertension in obese patients $\left(>60 \%\right.$ ) account for $78 \%$ of incident of hypertension in men and $64 \%$ in women ${ }^{15}$.

Although the classification system of obesity is not exactly identical, body mass index(BMI) is the most commonly used measure, dividing obesity into overweight and various grades ${ }^{16,17}$. Obesity has been shown to be associated with a variety of diseases, such as cancer ${ }^{18}$, hypertension, dyslipidemia, diabetes and cardiovascular disease $(\mathrm{CVD})^{19-21}$. There are few studies to quantify the relationship between BMI levels and hypertension, especially using some intuitive methods such as restricted cubic splines (RCS) ${ }^{22}$. Moreover, nobody has quantified the relationship between BMI levels and hypertension based on the population of Northeast China ${ }^{15}$.

The purpose of this study is to analyse the relationship between BMI and hypertension in people in northeast China. In our study, we used RCS function in dose-response analysis to adjust potential confounding factors to quantify the association between BMI and hypertension. In this way, our study can provide information for people's health promotion.

\section{Methods}

Study design. The study which was carried out in Jilin Province was a community-based, cross-sectional study. It starting from June 2012 and ended in August 2012. Research object of the study was the people aged between 18 and 79 years old, and the people must have lived in Jilin Province for more than 6 months. Multistage stratified cluster sampling was used to select research object from cities representative of the distribution of the Jilin population. The detailed sampling procedure had described previously ${ }^{23,24}$. The Ethics Committee of Jilin University School of Public Health approved the study (Reference Number: 2012-R-011). Before participating in this survey, all participants had provided informed consent.

Definitions. BMI was defined as the ratio of body weight (kilograms) to the square of height (meters). Based on the Chinese criteria of weight for adults, $\mathrm{BMI}<18.5,18.5 \leq \mathrm{BMI}<24.0,24.0 \leq \mathrm{BMI}<28.0, \mathrm{BMI} \geq 28.0$ were respectively defined as underweight, normal, overweight and obese ${ }^{22}$. Hypertension was defined as systolic $\geq 140 \mathrm{mmHg}$ and/or diastolic $\geq 90 \mathrm{mmHg}$ following the Chinese Hypertension Prevention Guide (2010 Revised Edition).According to WHO criteria(1999): Through glucoseoxidase method, FPG 7.0 mmol/L and/or $2 \mathrm{hPG} 11.1 \mathrm{mmol} / \mathrm{L}$ were regarded as diabetes. Abnormal blood lipids $(\mathrm{TC} \geq 5.18 \mathrm{mmol} / \mathrm{L}$ or TG $\geq 1.70 \mathrm{mmol} / \mathrm{L}$ or $\mathrm{HDL}-\mathrm{C}<1.04 \mathrm{mmol} / \mathrm{L}$ or LDL-C $\geq 3.37 \mathrm{mmol} / \mathrm{L}$ ) was diagnosed as hyperlipidemia based on the criteria of the "Chinese Guidelines on Prevention and Treatment of Dyslipidemia in Adults".

Occupations were classified into 3 groups: mental labor, manual labor, and retirees or unemployed. Mental labor was defined as the person who was managers, administrators, or technicians. The people who worked in the manufacturing industry, agriculture, or service industry were classified into manual labor. According to average monthly household, household incomes were classified into6 categories: below 500 yuan, 500 to $<1000$ yuan, 1000 to $<2000$ yuan, 2000 to $<3000$ yuan, 3000 to $<5000$ yuan, $\geq 2000$ yuan. Smoking was defined as never, ever (smoking at least 100 cigarettes in their lifetime but did not smoke at all), or current. Drinking habits provided two options-" 0 " and " 1 ". " 0 " was defined as no smoking, and " 1 " was defined as smoking. Exercise habits were classified into 3 categories based on exercise frequency. The exercise frequency of $\geq 3$ times a week was defined as "often exercise", once or twice a week was defined as "sometimes exercise", the others were defined as "never or rare exercise".

Statistical analysis. Demographics are presented as numbers and frequency distributions for categorical variables as appropriate. Univariate logistic regression analyses were used to determined significant differences between hypertension and nohypertension individuals. The association between BMI and hypertension was investigated by using unconditional multivariable logistic regression models and models which adjusted for age, gender, education level, and other variables, and to evaluate the potential confounding effects among risk factor variables. Multivariable-adjusted odds ratios(ORs) and their 95\% confidence intervals (CIs) in 3 different logistic regression models were calculated by the SPSS statistical package, version 19.0 (IBM Corp, Armonk, NY) independently. RCS were used to detect the possible nonlinear dependency of the relationship between the risk of hypertension and BMI levels, using 4 knots at prespecified locations according to the percentiles of the distribution of BMI, $18 \mathrm{~kg} / \mathrm{m}^{2}, 22 \mathrm{~kg} / \mathrm{m}^{2}, 25 \mathrm{~kg} / \mathrm{m}^{2}, 27 \mathrm{~kg} / \mathrm{m}^{222}$. Stata 12.0 (StataCorp, College Station, TX) was used to carry out the above-mentioned dose-response analyses. A significance level of $\mathrm{P}<0.05$ (2-tailed tests) was used.

\section{Results}

Characteristics of the study population. A total of 21,435 samples participated in our study, screened for data and eventually included in the study for 20,839 by deleting the missing height/weight values. Among the 20,839 participants, the prevalence of hypertension was $35.66 \%(7,431 / 20,839)$, with a number of 3,836 for male and 3,595 for female. The mean age was $(47.27 \pm 13.34)$ years. Compared with hypertension participants, the no hypertension individuals had a lower BMI $\left(23.46 \pm 3.55 \mathrm{~kg} / \mathrm{m}^{2}\right.$ vs $\left.25.58 \pm 3.65 \mathrm{~kg} / \mathrm{m}^{2}, \mathrm{P}<0.001\right)$.

The key variables for hypertension and no hypertension considered in our study are listed in Table 1. Significant differences were found in variables gender,age, residential areas, education, marital status, occupation, household income, smoker, drinking, and exercise $(\mathrm{P}<0.001)$.

Univariate and multivariate logistic regression analyses for investigation of the association between BMI and hypertension. Table 2 showed the results of univariate and multivariate logistic regression analyses. With the BMI classification as the only covariate, the ORs applied by unadjusted univariate logistic regression model were $0.40(95 \% \mathrm{CI}=0.33-0.49)$ for underweight, $2.17(95 \% \mathrm{CI}=2.0-2.32)$ for overweight, $3.79(95 \% \mathrm{CI}=3.48-4.13)$ for obesity $(P$ value $<0.001)$. After adjustment for age and gender, the adjusted odds ratios showed a consistent association between BMI classification and hypertension across the model. In a fully adjusted model, the impact of BMI was slightly diminished when adjusting for residential areas, education, 


\begin{tabular}{|c|c|c|c|c|c|}
\hline Variables & $\begin{array}{l}\text { Hypertension } \\
\text { (7431) }\end{array}$ & $\begin{array}{l}\text { No hypertension } \\
\text { (13408) }\end{array}$ & OR(95\%CI) & $x^{2}$ & $P$ Value \\
\hline Gender & & & & 83.44 & $<0.001$ \\
\hline Male & 3836 & 6037 & 1.000 & & \\
\hline Female & 3595 & 7371 & $0.768(0.725-0.812)$ & & \\
\hline Age(years) & & & & \begin{tabular}{|l|}
2674.798 \\
\end{tabular} & $<0.001$ \\
\hline $18-34$ & 417 & 3498 & 1.000 & & \\
\hline $35-44$ & 1101 & 3648 & $2.532(2.241-2.860)$ & & \\
\hline $45-54$ & 2255 & 3372 & 5.610(5.002-6.291) & & \\
\hline $55-64$ & 2351 & 2132 & $9.250(8.227-10.401)$ & & \\
\hline $65-79$ & 1307 & 758 & 14.464(12.633-16.560) & & \\
\hline Residential areas & & & & 32.925 & $<0.001$ \\
\hline Urban & 3629 & 7104 & 1.000 & & \\
\hline Rural & 3802 & 6304 & $1.181(1.116-1.250)$ & & \\
\hline Education & & & & 407.698 & $<0.001$ \\
\hline \multicolumn{6}{|l|}{ Primary school } \\
\hline or less & 2697 & 3446 & 1.000 & & \\
\hline Junior high school & 2142 & 3835 & $0.714(0.663-0.768)$ & & \\
\hline Senior high school & 1799 & 3550 & $0.647(0.600-0.699)$ & & \\
\hline University or above & 793 & 2577 & $0.393(0.358-0.432)$ & & \\
\hline Marital status & & & & 38.898 & $<0.001$ \\
\hline Married & 6520 & 11341 & 1.000 & & \\
\hline Single/divorced/widowed & 911 & 2067 & $0.767(0.705-0.834)$ & & \\
\hline Occupation & & & & 484.427 & $<0.001$ \\
\hline Mental workers & 1119 & 3103 & 1.000 & & \\
\hline Manual workers & 3959 & 7730 & $1.420(1.313-1.536)$ & & \\
\hline Others & 2353 & 2575 & $2.534(2.320-2.768)$ & & \\
\hline Household income & & & & 204.901 & $<0.001$ \\
\hline$<500$ & 1813 & 2424 & 1.000 & & \\
\hline $500 \sim$ & 1489 & 2392 & $0.832(0.762-0.910)$ & & \\
\hline $1000 \sim$ & 2391 & 4449 & $0.719(0.664-0.777)$ & & \\
\hline $2000 \sim$ & 1154 & 2677 & $0.576(0.526-0.632)$ & & \\
\hline $3000 \sim$ & 584 & 1466 & $0.533(0.475-0.597)$ & & \\
\hline Smoker & & & & 156.842 & $<0.001$ \\
\hline Never & 4248 & 8463 & 1.000 & & \\
\hline Ever & 818 & 858 & $1.899(1.714-2.105)$ & & \\
\hline \multirow[t]{2}{*}{ Current } & 2365 & 4087 & $1.153(1.083-1.2271)$ & & \\
\hline & & & & 41.831 & $<0.001$ \\
\hline No & 4891 & 9407 & 1.000 & & \\
\hline Yes & 2540 & 4001 & $1.221(1.149-1.297)$ & & \\
\hline Exercise & & & & 422.1796 & $<0.001$ \\
\hline Often & 2842 & 3369 & 1.000 & & \\
\hline Occasionally & 1423 & 3584 & $0.471(0.4352-0.509)$ & & \\
\hline Never & 3166 & 6455 & $0.581(0.545-0.621)$ & & \\
\hline BMI & & & & 1401.501 & $<0.001$ \\
\hline Normal & 2433 & 7058 & 1.000 & & \\
\hline Underweight & 114 & 827 & $0.400(0.327-0.489)$ & & \\
\hline Overweight & 3125 & 4177 & $2.170(2.033-2.317)$ & & \\
\hline Obesity & 1759 & 1346 & $3.791(3.483-4.126)$ & & \\
\hline
\end{tabular}

Table 1. Characteristics of the Study Population $(\mathrm{N}=20839)$, 2012,jilin Province, China. Abbreviations: OR, odds ration; CI, confidence interval; BMI, body mass index $\left(\mathrm{kg} / \mathrm{m}^{2}\right)$; DM, diabetes mellitus.

marital status, occupation, household income, smoking and drinking status, exercise. Although the association of BMI classification with hypertension prevalence was reduced with sequential adjustments, BMI showed a significant and clear gradient from the lowest underweight to the highest obesity level.

Dose-response relationship between BMI and hypertension. Based on the stratification of gender and age, we used RCS model with 4knots to simulate the relationship between BMI and the risk for hypertension. Significant nonlinear dose-response association was showed in the relationship between BMI and the risk of 


\begin{tabular}{|c|c|c|c|c|c|}
\hline Model Adjustment & $\begin{array}{l}\text { BMI } \\
\text { Classification }\end{array}$ & SE & Wald & $P$ & OR $(95 \% \mathrm{CI})$ \\
\hline \multirow{4}{*}{ Univariate Analysis } & $<18.5 \sim$ & 0.103 & 79.753 & $<0.001$ & $0.400(0.327-0.489)$ \\
\hline & $18.5 \sim$ & & 1315.667 & & $\operatorname{Ref}(1.000)$ \\
\hline & $24.0 \sim$ & 0.033 & 539.909 & $<0.001$ & $2.170(2.033-2.317)$ \\
\hline & $28.0 \sim$ & 0.043 & 952.685 & $<0.001$ & $3.791(3.483-4.126)$ \\
\hline \multirow{4}{*}{ Adjust Model ${ }^{\mathrm{a}}$} & $<18.5 \sim$ & 0.111 & 67.019 & $<0.001$ & $0.403(0.324-0.501)$ \\
\hline & $18.5 \sim$ & & 1194.594 & & $\operatorname{Ref}(1.000)$ \\
\hline & $24.0 \sim$ & 0.036 & 396.814 & $<0.001$ & $2.046(1.907-2.195)$ \\
\hline & $28.0 \sim$ & 0.047 & 949.563 & $<0.001$ & $4.237(3.865-4.644)$ \\
\hline \multirow{4}{*}{ Adjust Model ${ }^{\mathrm{b}}$} & $<18.5 \sim$ & 0.112 & 66.095 & $<0.001$ & $0.404(0.325-0.502)$ \\
\hline & $18.5 \sim$ & & 1178.959 & & $\operatorname{Ref}(1.000)$ \\
\hline & $24.0 \sim$ & 0.036 & 394.961 & $<0.001$ & $2.503(1.912-2.204)$ \\
\hline & $28.0 \sim$ & 0.047 & 943.510 & $<0.001$ & $4.259(3.883-4.671)$ \\
\hline
\end{tabular}

Table 2. Logistic regression analyses of the association between BMI and hypertension, 2012, Jilin Province, China. Model ${ }^{\mathrm{a}}$ : adjusted for baseline gender and age. Model $\mathrm{l}^{\mathrm{b}}$ : adjusted for baseline gender, age, residential areas, education, marital status, occupation, household income, smoking and drinking status, exercise.

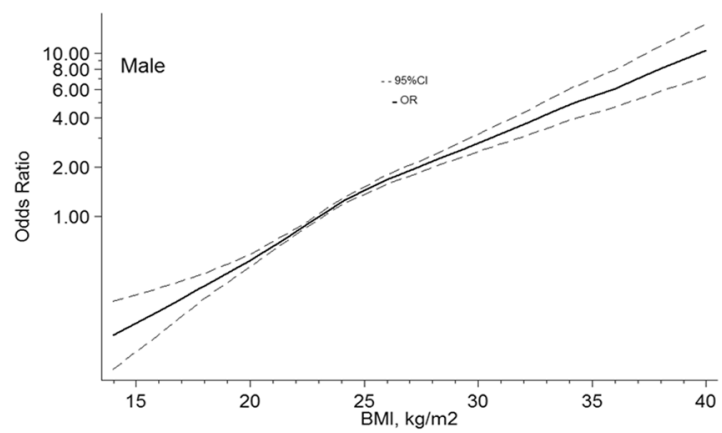

Figure 1. Association between BMI and the risk of hypertension in males, allowing for nonlinear effects, with $95 \% \mathrm{CI}$. The model shows ORs compared with BMI $23 \mathrm{~kg} / \mathrm{m}^{2}$, adjusting age, drinking, and residential areas. $\mathrm{BMI}$, body mass index; CI, confidence interval; OR, odds ratio.

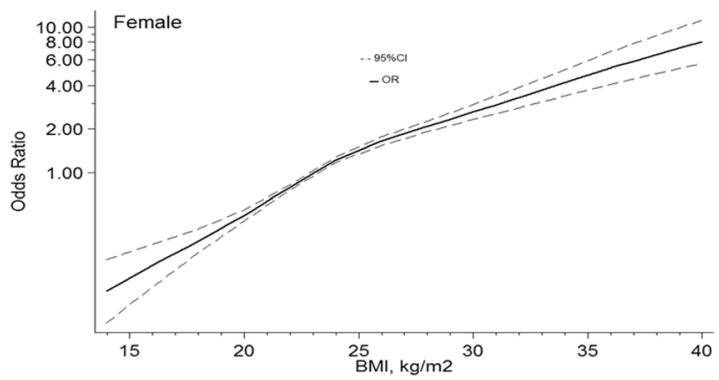

Figure 2. Association between BMI and the risk of hypertension in female, allowing for nonlinear effects, with $95 \%$ CI. The model shows ORs compared with BMI $23 \mathrm{~kg} / \mathrm{m}^{2}$, adjusting age, smoker, and residential areas. BMI, body mass index; CI, confidence interval; OR, odds ratio.

hypertension (all P value of nonlinear $<0.001$ ). And dose-response relationship analysis showed that with the continuous change of BMI, the association strength of hypertension increased nonlinearly.

In males, with $23 \mathrm{~kg} / \mathrm{m}^{2}$ of BMI as a reference, the ORs and $95 \%$ CIs of the $4 \mathrm{knots}$ of BMI were $0.37(0.31-$ $0.45)$ for $18 \mathrm{~kg} / \mathrm{m}^{2}, 0.81(0.77-0.84)$ for $22 \mathrm{~kg} / \mathrm{m}^{2}, 1.46(1.36-1.55)$ for $25 \mathrm{~kg} / \mathrm{m}^{2}, 1.91(1.78-2.06)$ for $27 \mathrm{~kg} / \mathrm{m}^{2}$. In females, ORs and $95 \%$ CIs of the 4 points of BMI at $18 \mathrm{~kg} / \mathrm{m}^{2}, 22 \mathrm{~kg} / \mathrm{m}^{2}, 25 \mathrm{~kg} / \mathrm{m}^{2}, 27 \mathrm{~kg} / \mathrm{m}^{2}$ were $0.34(0.28-0.41)$, $0.80(0.76-0.83), 1.46(1.36-1.55)$, and 1.86(1.73-2.01). Figures 1 and 2 showed the nonlinear dose-response association, with confounders being adjusted.

Similar relationships between hypertension risk and BMI were found in different age groups when using 4 knots (all P value of nonlinear $<0.001$; Fig. 3). In young adults (18-44 years old), the points of BMI at $18 \mathrm{~kg} / \mathrm{m}^{2}$ and $22 \mathrm{~kg} / \mathrm{m}^{2}$ were, whereas $25 \mathrm{~kg} / \mathrm{m}^{2}$ and $27 \mathrm{~kg} / \mathrm{m}^{2}$ were $0.27(0.21-0.36), 0.73(0.69-0.77), 1.65(1.51-1.81)$, and 2.14(1.95-2.36). For middle-aged adults (45-59 years old) and older adults (65-79 years old), the ORs ( $95 \%$ CIs) 

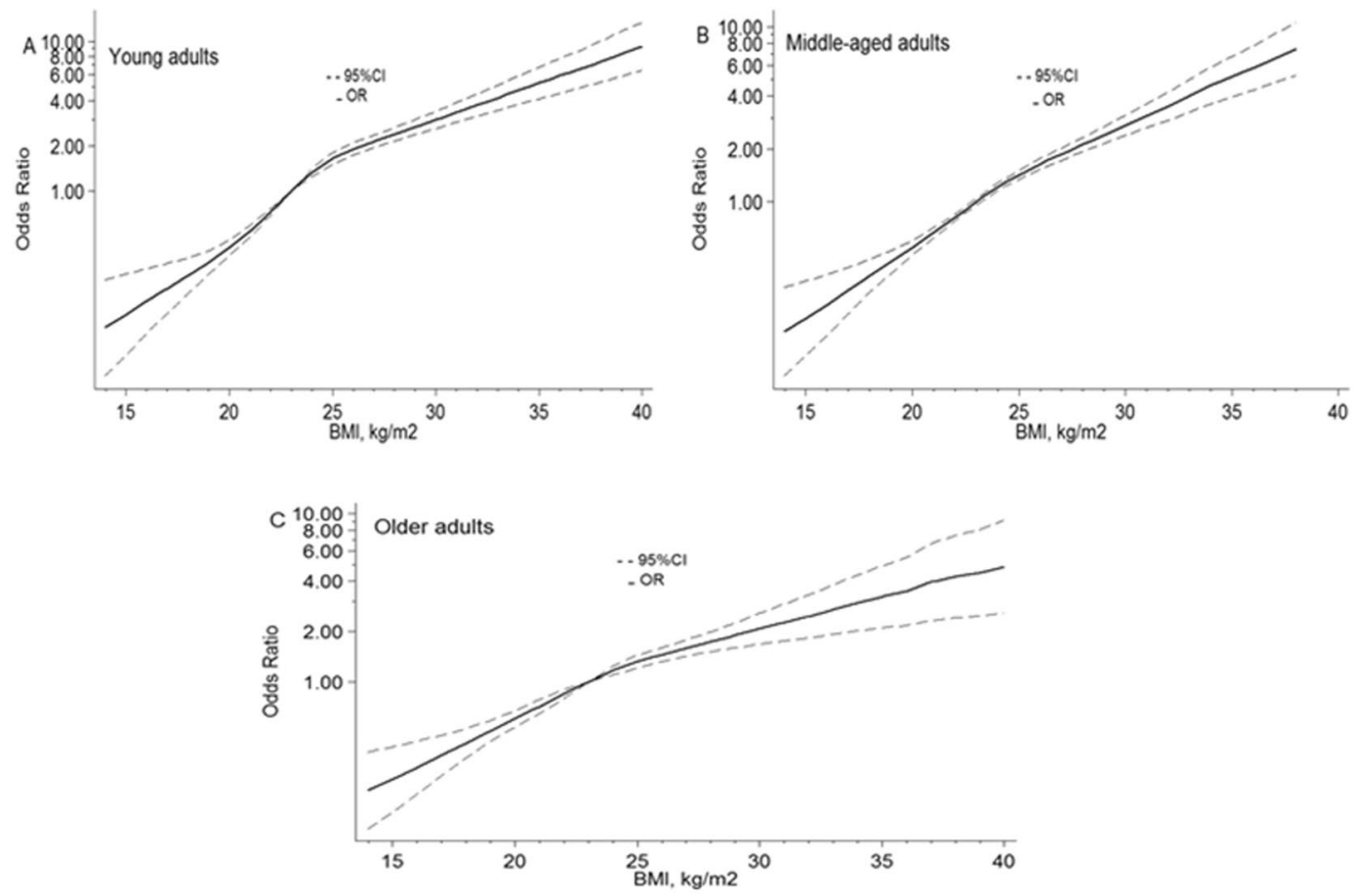

Figure 3. Association between BMI and the risk of hypertension in female, allowing for nonlinear effects, with 95\%CI. (A) Young adults. Using 4 knots restricted cubic spline for BMI model adjusted gender, residential areas, occupation, smoker, drinking exercise, marital status, and education. (B) Middle-aged adults. Using 4 knots restricted cubic spline for BMI model adjusted gender, smoker, drinking, and exercise. (C) Older adults. Using 4 knots restricted cubic spline for BMI model adjusted gender, smoker, and exercise.BMI, body mass index; CI, confidence interval; OR, odds ratio.

for hypertension risk were for BMI at $18 \mathrm{~kg} / \mathrm{m}^{2}$ were $0.38(0.30-0.47)$ and $0.43(0.35-0.53)$, at $22 \mathrm{~kg} / \mathrm{m}^{2}$ were $0.81(0.77-0.85)$ and $0.85(0.80-0.90)$, where as at $25 \mathrm{~kg} / \mathrm{m}^{2}$ were $1.43(1.34-1.53)$ and $1.32(1.21-1.44)$, at $27 \mathrm{~kg} / \mathrm{m}^{2}$ were $1.87(1.73-2.02)$ and 1.59(1.43-1.78). All age groups are referenced to BMI $23 \mathrm{~kg} / \mathrm{m}^{2}$. Three groups adjusted forpotential confounders that were tailored to the specific population.

\section{Discussion}

In the population-based study of Jilin Province in Northeastern China, our study reported the prevalence of hypertension was $35.66 \%$ including previously diagnosed hypertension and newly diagnosed hypertension. Regardless of gender or age, after adjusting for confounding factors, continuous changes in BMI are significantly associated with the risk of hypertension. And dose-response relationship analysis showed that with the continuous change of BMI, the association strength of hypertension increased nonlinearly.

On a national scale in China, findings based on different backgrounds' survey in the past 30 years basically showed an upward trend in the prevalence of hypertension ${ }^{25}$. Chinas chronic disease monitoring in 2010 reported that the national prevalence of hypertension was $33.5 \%$, which was lower than the rate of $35.66 \%$ reported by our study $^{26}$. Our rate was higher than the rate of $17.2 \%$ displayed by the monitoring results of Kunshan city in the same year ${ }^{22}$, but not reached the rate of $38.6 \%$ of Jiangsu Province ${ }^{27}$.

As early as 1996, study ${ }^{19}$ showed that the increasing of BMIs can make blood pressure increase, which indicated that there was not only a strong relationship between BMI and hypertension, but also was an association between the continuous variables of BMI and blood pressure. Our study and the study ${ }^{22}$ conducted in kunshan city confirmed that there was nonlinear dose-response relationship between BMI and the risk of hypertension.

Although the mechanism of how obesity caused hypertension was not yet clear, epidemiological evidence had highlighted that there was a consistent correlation between obesity and hypertension, and obesity predisposes hypertension ${ }^{28}$. The pathophysiological explanation of obesity predisposing hypertensionis elevated cardiac output, which perhaps attribute to excess intravascular volume and reduced cardiac contractility ${ }^{29}$. There was evidence suggested that in obesity individual, nutritional status alteration, gut microbiota, sunlight exposure and physical activity increase played an important role in the hypertension or not ${ }^{30}$. Further research investigating dose-response association between BMI and hypertension would be a significant step to decrease the social burden of hypertension.

\section{Conclusion}

Our outcomes demonstrated that dose-response relationship exists between BMI and hypertension, and increased $\mathrm{BMI}$ is an independent and adjusted dose-dependent risk factor for hypertension among overweight and obesity participants in China. 
Received: 11 April 2018; Accepted: 14 November 2019;

Published online: 03 December 2019

\section{References}

1. Freire, I. V., Casotti, C. A. \& Ribeiro, I. J. S. Daily sodium intake influences the relationship between angiotensin-converting enzyme gene insertion/deletion polymorphism and hypertension in older adults. 20, 541-550, https://doi.org/10.1111/jch.13224 (2018).

2. Addo, J., Smeeth, L. \& Leon, D. A. Hypertension in sub-saharan Africa: a systematic review. Hypertension 50, 1012 (2007).

3. Wong, N. D. \& Franklin, S. S. Reducing the Burden of Hypertension: China’s Long March Ahead. Jama Intern Med, 176 (2016).

4. Lewington, S. et al. The Burden of Hypertension and Associated Risk for Cardiovascular Mortality in China. Jama Internal Medicine 176, 524 (2016)

5. Li, W. et al. Hypertension prevalence, awareness, treatment, and control in 115 rural and urban communities involving $47 \hat{a}$ Š000 people from China. Journal of Hypertension 34, 39-46 (2016).

6. Wang, Y. et al. Burden of hypertension in China over the past decades: Systematic analysis of prevalence, treatment and control of hypertension. European Journal of Preventive Cardiology 23, 792 (2016).

7. Drenjančevićperić, I. et al. High-Salt Diet and Hypertension: Focus on the Renin-Angiotensin System. Kidney \& Blood Pressure Research 34, 1 (2011).

8. Organization, W. H. Sodium intake for adults and children. World Health Organization (2012).

9. Poch, E. et al. Molecular basis of salt sensitivity in human hypertension. Evaluation of renin-angiotensin-aldosterone system gene polymorphisms. Hypertension 38, 1204 (2001).

10. Montgomery, H. et al. Angiotensin-converting-enzyme gene insertion/deletion polymorphism and response to physical training. Lancet 353, 541-545 (1999).

11. Ogden, C. L., Carroll, M. D., Kit, B. K. \& Flegal, K. M. Prevalence of childhood and adult obesity in the United States, 2011-2012. Jama 311, 806 (2014).

12. Ng, M. et al. Global, regional, and national prevalence of overweight and obesity in children and adults during 1980-2013: a systematic analysis for the Global Burden of Disease Study 2013. Lancet 384, 766 (2014).

13. Wang, Y. \& Wang, Q. J. The prevalence of prehypertension and hypertension among US adults according to the new Joint National Committee Guidelines. Archives of Internal Medicine 164, 2126 (2004).

14. Lewis, L. et al. Obesity-related hypertension: pathogenesis, cardiovascular risk, and treatment: a position paper of The Obesity Society and the American Society of Hypertension. Journal of Clinical Hypertension 15, 14-33 (2013).

15. Kannel, W. B., Brand, N. S. J. Jr., Dawber, T. R. \& Mcnamara, P. M. The relation of adiposity to blood pressure and development of hypertension. The Framingham study. Annals of Internal Medicine 67, 48-59 (1967).

16. Gómez-Ambrosi, J. et al. Body Adiposity and Type 2 Diabetes: Increased Risk With a High Body Fat Percentage Even Having a Normal BMI. Obesity 19, 1439-1444 (2011).

17. Bays, H. E., Chapman, R. H. \& Grandy, S. The relationship of body mass index to diabetes mellitus, hypertension and dyslipidaemia: comparison of data from two national surveys. International Journal of Clinical Practice 61, 737-747 (2007).

18. Xia, X. et al. Body Mass Index and Risk of Breast Cancer: A Nonlinear Dose-Response Meta-Analysis of Prospective. Studies. Scientific Reports 4, 7480 (2014).

19. Jones, D. W. Body Weight and Blood Pressure Effects of Weight Reduction on Hypertension. American Journal of Hypertension 9 , 50s (1996).

20. Khaodhiar, L., Cummings, S. \& Apovian, C. M. Treating diabetes and prediabetes by focusing on obesity management. Current Diabetes Reports 9, 348-354 (2009).

21. Grundy, S. M. Obesity, metabolic syndrome, and cardiovascular disease. Journal of Clinical Endocrinology \& Metabolism 89, 2595 (2004).

22. Hu, W. et al. Analysis of relationship between dose-response and intensity of BMI and hypertension. Chinese health statistics 32, 971-974 (2015).

23. Wang, C. et al. Awareness, treatment, control of diabetes mellitus and the risk factors: survey results from northeast China. Plos One 9, e103594 (2014).

24. Research, I. J. O. E. \& Office, P. H. E. Erratum: Li, Z. et al. Smoking Prevalence and Associated Factors as well as Attitudes and Perceptions towards Tobacco Control in Northeast China. Int. J. Environ. Res. Public Health 2015, 12, 8606-8618. International Journal of Environmental Research \& Public Health13 (2016).

25. Wang, J., Zhang, L., Wang, F., Liu, L. \& Wang, H. Prevalence, awareness, treatment, and control of hypertension in China: results from a national survey. American Journal of Hypertension 27, 1355 (2014)

26. Li, Y. et al. Prevalence of hypertension in Chinese adults in 2010. Chinese Journal of Preventive Medicine 46, 409-413 (2012).

27. Liu, J. et al. The Blood Pressure Change of Residents in Jiangsu Province and Its Relationship with BMI and Waist Circumference. Chinese public health 29, 792-795 (2013).

28. Ruilope, L. M., Nunes, A. F., Nadruz, J. W., Rodríguez, F. R. \& Verdejoparis, J. Obesity and hypertension in Latin America: Current perspectives. Hipertension Y Riesgo Vascular (2018).

29. Babu, G. R. et al. Association of obesity with hypertension and type 2 diabetes mellitus in India: A meta-analysis of observational studies. World Journal of Diabetes 9,40 (2018).

30. Kotsis, V. et al. New developments in the pathogenesis of obesity-induced hypertension. Journal of Hypertension 33, 1499-1508 (2015)

\section{Acknowledgements}

Thanks for all the participants and reviewers in Jilin Province of China and the support of the Center for Disease Prevention and Control in Jilin Province. The study was supported by grants from the Scientific Research Foundation of the Health Bureau of Jilin Province, China (Grant Number: 2011Z116).

\section{Author contributions}

Qu Yangming, Niu Huikun and Li Bo conceptualized and designed the study, drafted the initial manuscript, and reviewed and revised the manuscript. Li Lu, Li Meiqi, Yan Shoumeng, Li Meng, Ma Xiaoyu and Jiang Shan designed the data collection instruments, collected data, carried out the initial analyses, and reviewed and revised the manuscript. Wu Hui conceptualized and designed the study, coordinated and supervised data collection, and critically reviewed the manuscript for important intellectual content. All authors approved the final manuscript as submitted and agree to be accountable for all aspects of the work.

\section{Competing interests}

The authors declare no competing interests. 
Additional information

Correspondence and requests for materials should be addressed to B.L. or H.W.

Reprints and permissions information is available at www.nature.com/reprints.

Publisher's note Springer Nature remains neutral with regard to jurisdictional claims in published maps and institutional affiliations.

(c) (i) Open Access This article is licensed under a Creative Commons Attribution 4.0 International License, which permits use, sharing, adaptation, distribution and reproduction in any medium or format, as long as you give appropriate credit to the original author(s) and the source, provide a link to the Creative Commons license, and indicate if changes were made. The images or other third party material in this article are included in the article's Creative Commons license, unless indicated otherwise in a credit line to the material. If material is not included in the article's Creative Commons license and your intended use is not permitted by statutory regulation or exceeds the permitted use, you will need to obtain permission directly from the copyright holder. To view a copy of this license, visit http://creativecommons.org/licenses/by/4.0/.

(C) The Author(s) 2019 